\title{
Phacoemulsification combined with micropulse cyclodiode laser in glaucoma patients: efficacy and safety
}

\author{
Arij Daas $^{1,2}$, Thomas Sherman (iD) ${ }^{1,2}$, Lina Danieliute ${ }^{1,2}$, Saurabh Goyal (iD ${ }^{1}$, Andrew Amon ${ }^{1}$, lan Rodrigues ${ }^{1}$, Ayesha Karimi ${ }^{2}$ and
} Kin Sheng $\operatorname{Lim}\left(\mathrm{ID}^{1,2}\right.$

(c) The Author(s) 2021

\begin{abstract}
OBJECTIVE: To evaluate the safety and efficacy of phacoemulsification combined with Micropulse transscleral cyclophotocoagulation (MP-TSCPC) in glaucoma patients.

METHODS: This is a retrospective case-note review. The participants were adult patients with diagnoses of glaucoma and cataract who required a further reduction in IOP or a reduction in the number of glaucoma drops. All consecutive patients who underwent cataract surgery (CS) combined with MP-TSCPC laser between October 2018 and July 2019 were included in the study. The effect on visual acuity (VA), intraocular pressure (IOP) and number of anti-glaucoma drops were evaluated at 6 and 12 months in addition to any complications that occurred during any time point of the study.

RESULTS: 42 eyes were included in the study. Mean IOP was reduced from $19.5 \pm 5.4 \mathrm{mmHg}$ by $22.5 \%$ to $15.1 \pm 4.6$ at 6 months post-operatively and by $19.5 \%$ to $15 \pm 6.6 \mathrm{~mm} \mathrm{Hg}$ at 12 months ( $p<0.001$ at both time points). The number of anti-glaucoma medications also reduced significantly from $2.8 \pm 1.3$ to $1.6 \pm 1.2$ at 6 months and to $2.2 \pm 1.3$ at 12 months $(p<0.001$ at both time points). The success rate was $56 \%$ at 6 months and $54 \%$ at 12 months. $54.7 \%$ of our patients who completed 12 months follow up had an improvement or unchanged vision at the last visits.

CONCLUSION: This is the first study evaluating the effect of cataract surgery combined with MP-TSCPC in glaucoma patients. We demonstrated that this led to a reduction in IOP and the number of anti-glaucoma medications at 6 and 12-month postoperatively. The majority of patients had either stable or better vision at 12 months follow-up.
\end{abstract}

Eye (2022) 36:2188-2191; https://doi.org/10.1038/s41433-021-01826-1

\section{INTRODUCTION}

Cataract and glaucoma are the leading causes of blindness worldwide [1, 2]. Cataract surgery (CS) is known to reduce IOP by increasing the outflow facility [3]. Micropulse transscleral cyclophotocoagulation (MP-TSCPC) laser is a cyclodestructive process that was first used in 2006; it attempts to reduce IOP by inducing cellular destruction of ciliary processes and associated vasculature, thereby reducing aqueous humour production. However, other theories have been speculated e.g. by Johnstone et al. suggesting that MP-TSCPC might have a similar effect to pilocarpine influencing aqueous humour outflow on ex-vivo study [4]. Previous clinical studies have shown a significant reduction in IOP after using MP-TSCPC in patients with glaucoma [5-8]. Combined procedures have shown a greater effect in reducing IOP in glaucoma patients [9]. The effect of CS combined with MPTSCPC treatment has never been studied. Therefore, we have performed a retrospective case series analysis of consecutive patients who underwent CS and MP-TSCPC between October 2018 and July 2019 to assess the efficacy of this combined procedure. The qualified success rate was defined as achieving a $20 \%$ reduction in IOP with no increase in medications and no further surgery. Secondary outcomes were the change in VA, IOP and the number of antiglaucoma drops used at 6- and 12-months post-surgery as well as any complications.

\section{METHODS}

This is a retrospective longitudinal study comparing the change in IOP, VA, and the number of antiglaucoma agents used by consecutive patients who underwent CS with MP-TSCPC at St. Thomas' Hospital between October 2018 and July 2019. The data are extracted from the electronic patient records and paper notes. For the purpose of this study, baseline up to 12 months postoperative follow up data were analysed. Phacoemulsification combined with MP-TSCPC was offered to optimise IOP in mild, moderate and advanced glaucoma patients who were undergoing cataract surgeries. Patients with normal tension glaucoma (NTG), open angle (OAG) and primary angle closure glaucoma (PACG) were included in the study, we have excluded patients with neovascular glaucoma and uveitic glaucoma from our study. Informed consent was obtained from patients undergoing surgery. We conducted the study within an ethical framework, as outlined in the Declaration of Helsinki.

\section{Surgical technique}

Surgery was performed by experienced surgeons, two consultants (KSL \& SG) and one glaucoma fellow. Peribulbar anaesthesia was performed prior to the combined procedures followed by Micropulse cyclodiode laser using the following parameters: $2 \mathrm{~W}$ delivered over $160 \mathrm{~s}$ with a sweeping motion avoiding the 3 and 9 o'clock positions. This was followed by uncomplicated cataract surgery performed with a standard phacoemulsification technique. All patients received intra-cameral cefuroxime $(0.1 \mathrm{mg} /$ $0.1 \mathrm{~mL}$ ) and dexamethasone $(0.2 \mathrm{~mL})$ at the end of the surgery. Topical and oral glaucoma medications were stopped on the operated eye at the time

${ }^{1}$ St Thomas' Hospital, London, United Kingdom. ${ }^{2}$ King's College London, London, United Kingdom. ${ }^{凶}$ email: shenglim@gmail.com 
of surgery. Patients were given chloramphenicol eye drops QDS for 1 week and dexamethasone preservative-free eye drops 2 hourly for 1 week on a tapering regime over the next 6 weeks.

\section{Follow up}

All patients had follow-up at 1 week, 3, 6 and 12 months. If they had any complications, the frequency of the follow up was adjusted according to clinical need.

\section{Data analysis}

Data were recorded on Microsoft Excel 2016 and statistical analysis was performed using SPSS 25.0; SPSS, Chicago, IL. Means with standard deviations (SD) were calculated for IOPs and means with 95\% confidence intervals were calculated where appropriate at all time points. The Chisquare goodness of fit test showed that IOP followed a normal distribution at all time points; therefore, the paired Student's $t$ test was used to compare baseline and postoperative mean IOP. One-way ANOVA was performed to compare the change in outcome measures during baseline and follow-up periods. A $p<0.05$ was considered statistically significant.

\section{RESULTS}

42 eyes were included in the study with 34 reaching 12 months follow up. Baseline demographics and clinical characteristics of the patients included in the study are shown in (Table 1) The mean baseline IOP was $19.5 \pm 5.4 \mathrm{mmHg}$ and ranged from 9 to 40 $\mathrm{mmHg}$. The mean IOP at 6 and 12 months was $15.1 \pm 4.6$ and 15.7 $\pm 6.6 \mathrm{mmHg}$, respectively (Fig. 1). This was a statistically significant

Table 1. Patient demographics.

\begin{tabular}{ll} 
No. of surgeries & $\mathbf{4 2}$ \\
Age, years & \\
\hline Mean (Range) & $74.9(53-89)$ \\
\hline Sex, $n$ (\%) & \\
\hline Male & $54.70 \%$ \\
\hline Female & $45.20 \%$ \\
\hline Ethnicity, $n$ (\%) & \\
\hline Afro-Caribbean & $40.40 \%$ \\
\hline White & $45.20 \%$ \\
\hline Asian & 11.9 \\
\hline Mixed (white \& Afro-Caribbean) & $2.30 \%$ \\
\hline Pre-op IOP, mmHg & \\
\hline Mean (95\% confidence interval) & $19.5(17.8-21.2)$ \\
\hline Range & $9-40$ \\
\hline No. of IOP lowering medications pre-op & \\
\hline Mean (95\% confidence interval) & $2.8(2.3-3.2)$ \\
\hline Range & $0-4$ \\
\hline Diagnoses, $n$ (\%) & \\
\hline POAG & $34(81.0)$ \\
\hline PACG & $4(9.5)$ \\
\hline NTG & $2(4.8)$ \\
\hline PDG & $1(2.4)$ \\
\hline OHT & $1(2.4)$ \\
\hline Glaucoma severity, $n$ (\%) & $18(42.9)$ \\
\hline Mild & $16(38.1)$ \\
\hline Moderate & \\
\hline Severe & \\
\hline PAG pimary & \\
\hline
\end{tabular}

POAG primary open angle glaucoma, PACG primary angle closure glaucoma, NTG normal tension glaucoma, PDG pigment dispersion glaucoma, OHT ocular hypertension. reduction at both follow-up timepoints, with a $p<0.001 .22 .5 \%$ and $19.5 \%$ IOP reduction was achieved at 6 - and 12-months follow-up, respectively. The mean number of antiglaucoma agents used at baseline was $2.8 \pm 1.3$ only one patient was on oral Acetazolamide. This reduced to $1.6 \pm 1.2$ and $2.2 \pm 1.3$ at 6 - and 12months and was statistically significant at both time points (Fig. 2) none of the patients required oral Acetazolamide at 12 months follow up. The overall success rate was $56 \%$ at 6 months and $54 \%$ at 12 months.

There was no statistically significant improvement on visual acuity, from ETDRS $74 \pm 17$ at baseline to $75 \pm 20$ at 12 months (Fig. 3). 42.8\% of our patients who completed 12 months follow up had an improvement in their visual acuity by 1 line or more, $11.9 \%$ had unchanged vision and $26.1 \%$ (11 patients) had worsening in their vision.

Complications included cystoid macular oedema (CMO), persistent anterior uveitis, persistent mydriasis, further surgery for glaucoma and visual acuity loss of $>2$ Snellen lines (Table 2). Five patients had cystoid macular oedema at the 3-month timepoint: Two of these cases improved by 6 months through drops and observation and one improved by 12 months after a subconjunctival triamcinolone injection. One patient that developed CMO had a previous branch retinal vein occlusion in the eye. Unfortunately, one patient had newly developed CMO that started 1 -week post-surgery, and this persisted beyond 12 months. Ten patients had anterior uveitis and two patients required anterior chamber (AC) tissue plasminogen activator (tPA) injection within the first three months post-op. One patient had persistent anterior chamber inflammation post-op twelve months whereas another case developed new AC activity at 12 months. Further glaucoma filtration surgery was required for five patients at different

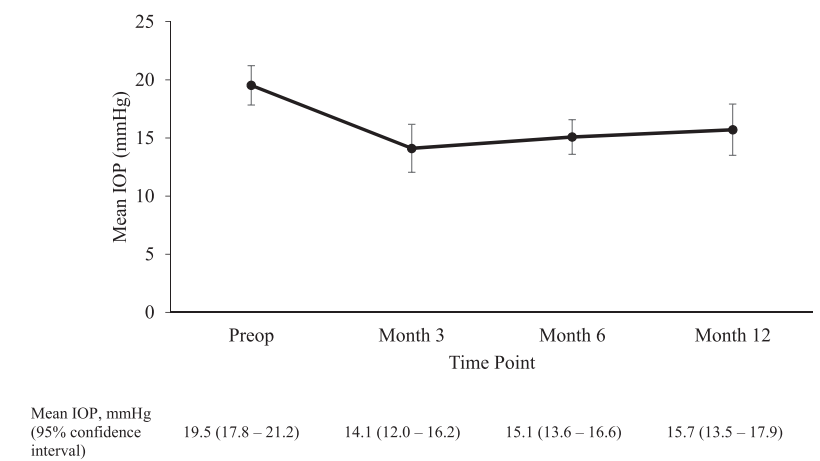

Fig. 1 Change in IOP over time. Mean IOP at pre- and postcombined MP-TSCPC and cataract surgery at Month 3, Month 6 and Month 12, shown with $95 \%$ confidence intervals.

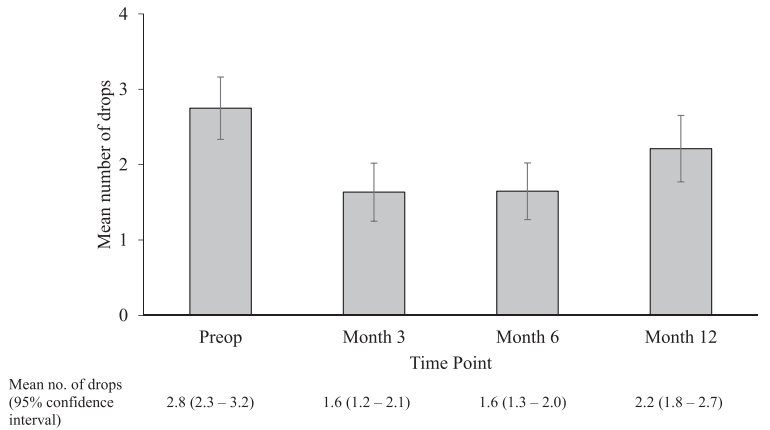

Fig. 2 Change in number of glaucoma eye drops over time. Mean number of drops at pre- and post- combined MP-TSCPC and cataract surgery at Month 3, Month 6 and Month 12, shown with $95 \%$ confidence intervals. 


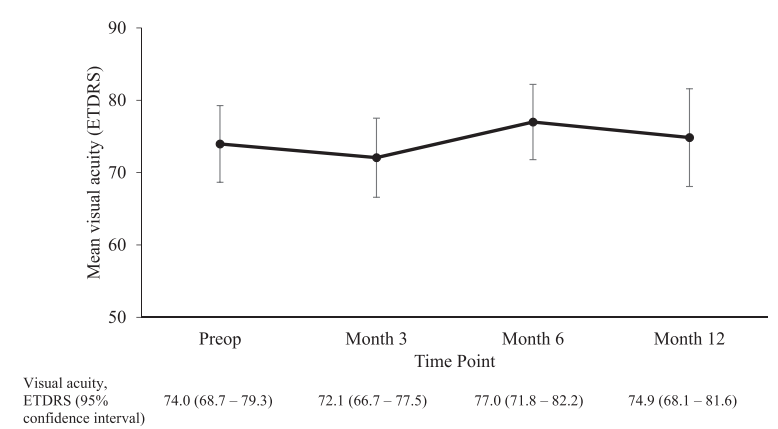

Fig. 3 Change in visual acuity over time. Mean visual acuity at preand post- combined MP-TSCPC and cataract surgery at Month 3, Month 6 and Month 12, shown with 95\% confidence intervals.

Table 2. Complications occurring at different timepoints following micropulse transscleral cyclophotocoagulation combined with cataract surgery.

\begin{tabular}{llll} 
Complication & $\mathbf{3}$ months & $\mathbf{6}$ months & $\mathbf{1 2}$ months \\
\hline Cystoid macular oedema & 5 & 0 & 1 \\
\hline Persistent anterior uveitis & 10 & 1 & 2 \\
\hline Persistent mydriasis & 2 & 1 & 0 \\
$\begin{array}{l}\text { Further surgery for } \\
\text { glaucoma }\end{array}$ & 1 & 3 & 1 \\
$\begin{array}{l}\text { VA loss of }>2 \text { Snellen lines } \\
\text { V }\end{array}$ & 6 & 0 & 5
\end{tabular}

timepoints, comprising of four trabeculectomies and one Baerveldt tube. Of these patients, two had primary open angle, two had primary angle closure and one patient had pseudoexfoliation glaucoma. Though six cases had a visual acuity loss of $>2$ Snellen lines at 3 months compared to preoperatively, five additional patients had a new visual acuity loss recorded at 12 months due to one case requiring a Trabeculectomy, one Baerveldt, one persistent anterior uveitis, one developed posterior capsular opacification and the reason for one was unknown.

\section{DISCUSSION}

This is the first study to evaluate the effect of CS combined with MP-TSCPC in glaucoma patients. We demonstrated that this was effective in reducing IOP and the need for anti-glaucoma drops at all timepoints.

Previous studies have found the decrease in IOP to be between 1.5 and $9.5 \mathrm{mmHg}$ after phacoemulsification [10-14]. The drop in IOP by $9.7 \%$ can persist up to 5 years follow-up in $76 \%$ of the glaucoma patients [13]. The reduction in IOP after MP-TSCPC however is reported to be $20-60 \%[5-7,15]$. We have demonstrated that IOP lowered by $22.5 \%$ at 6 months and $19.5 \%$ at 12 months follow-up when cataract surgery was combined with MP-TSCPC.Though the IOP appeared to increase up to the month 12 timepoint, this was not statistically significant ( $p: 0.19)$.

Although the level of IOP lowering appeared to be similar to some studies following CS alone, our result compared well with another study from our unit [3] where CS alone achieved a $12 \%$ reduction of IOP at 3 months. This shows there may be confounding factors in the difference in IOP reduction compared to other studies, including patient cohort, surgical technique, drop choice, etc. The reduction in IOP can be explained by the increase in tonographic outflow facility after CS [3] and also by the decrease in aqueous humour production, which is the most widely held view regarding the mechanism of IOP reduction post MPTSCPC. The change in anti-glaucoma drops was consistent with Tan et al.'s findings [6].
The change in IOP at 6 and 12 months after receiving MP-TSCPC alone have been inconsistent in previous studies. In the report by Zaarour et al. [15], it was found that the mean IOP reduced from month 6-12 and this may have been due to IOP-raising postoperative inflammation, which improved by 12 months as compared to 6 months. Others have reported unchanged IOP with time [16]. Data on this are conflicting, and all are based on MPTSCPC alone, rather than combined with cataract surgery as in our study. We found that IOPs after surgery overall started to rise by 12 months compared to 6 months, which is the general trend following majority of glaucoma and cataract surgeries.

Our study demonstrated that $42.8 \%$ of our patients who completed 12 months follow up had an improvement in their visual acuity by 1 line or more, $11.9 \%$ had unchanged vision and $26.1 \%$ (11 patients) had worsening in their vision. We explored the patients who had worsening in vision and found: 2 patients had further glaucoma filtrating surgeries, 2 patients had CMO, 1 patient had persistent inflammation, and 1 patient had posterior capsular opacification at 12 months follow up.

The incidence of $\mathrm{CMO}$ has been reported to be between $1 \%$ and $30 \%[17,18]$ after non-complicated cataract surgery and $5 \%$ after only MP-TSCPC [19]. Two patients developed CMO which was persistent at the 1 year follow up. One of these patients had a previously established branch retinal vein occlusion in the operated eye as a confounding factor, and the other had severe anterior chamber inflammation and presented with CMO 1 week postoperatively. We found that severe inflammation in the early days post-surgery may be an indication towards poor prognosis long term. Therefore, aggressive anti-inflammatory treatment should be considered early. Perez et al. reported neurotrophic keratitis in two patients after receiving MP-TSCPC [20]. However, our study did not show any patients with this complication.

Our study demonstrates promising results, longer follow-up should be sought to assess the influence on IOP reduction beyond 12 months. A randomised trial could be considered comparing phacoemulsification alone versus phacoemulsification with MPTSCPC in one type of glaucoma, such as OAG, to truly understand the many factors affecting IOP reduction.

\section{Summary}

What was known before

- Cataract surgery is known to reduce the intra-ocular pressure by increasing the outflow facility.

- Micropulse cyclodiode laser is also known to reduce the intraocular pressure.

- The effect of cataract surgery combined with Micropulse cyclodiode laser has never been studies.

What this study adds

- This is the first study to evaluate the effect of cataract surgery combined with micropulse cyclodiode laser in glaucoma patients.

- We demonstrated that this was effective in reducing IOP and the need for anti-glaucoma drops at all timepoints.

\section{REFERENCES}

1. Abraham AG, Condon NG, West Gower E. The new epidemiology of cataract. Ophthalmol Clin North Am. 2006;19:415-25.

2. Quigley HA, Broman AT. The number of people with glaucoma worldwide in 2010 and 2020. Br J Ophthalmol. 2006;90:262 LP-267.

3. Alaghband P, Beltran-Agulló L, Galvis EA, Overby DR, Lim KS. Effect of phacoemulsification on facility of outflow. Br J Ophthalmol. 2018;102:1520-6. 
4. Johnstone M, American JM-27th AM of the, 2017 undefined. Transcleral Laser Induces Aqueous Outflow Pathway Motion \& Reorganization. https://www.iridex. wsivirtual.com/portals/0/pdf/Transcleral-induces-aqueous-outflow-pathwaymotion-and-reorganization-Dr.pdf. Accessed 11 December 2019.

5. Aquino MCD, Barton K, Tan AMWT, et al. Micropulse versus continuous wave transscleral diode cyclophotocoagulation in refractory glaucoma: a randomized exploratory study. Clin Exp Ophthalmol. 2015;43:40-6.

6. Tan AM, Chockalingam M, Aquino MC, Lim ZIL, See JLS, Chew PT. Micropulse transscleral diode laser cyclophotocoagulation in the treatment of refractory glaucoma. Clin Exp Ophthalmol. 2010;38:266-72.

7. Emanuel ME, Grover DS, Fellman RL, et al. Micropulse cyclophotocoagulation: initial results in refractory glaucoma. J Glaucoma. 2017;26:726-9.

8. Hui $L$, Shi $Y$, Amoozgar B, et al. Outcome of micropulse laser transscleral cyclophotocoagulation on pediatric versus adult glaucoma patients. J Glaucoma. 2017;26:936-9.

9. Samuelson TW, Chang DF, Marquis R, Flowers B, Sheng LK, Ahmed IIK, et al. A Schlemm canal microstent for intraocular pressure reduction in primary openangle glaucoma and cataract: the HORIZON study. Ophthalmology. 2019;126:29-37.

10. Merkur A, Damji KF, Mintsioulis G, Hodge WG. Intraocular pressure decrease after phacoemulsification in patients with pseudoexfoliation syndrome. J Cataract Refract Surg. 2001;27:528-32.

11. Mathalone N, Hyams M, Neiman S, Buckman G, Hod Y, Geyer O. Long-term intraocular pressure control after clear corneal phacoemulsification in glaucoma patients. J Cataract Refract Surg. 2005;88:S21-5.

12. Peräsalo R. Phaco-emulsification of cataract in eyes with glaucoma. Acta Ophthalmol Scand. 1997;75;299-300.

13. Shingleton BJ, Pasternack JJ, Hung JW, O'Donoghue MW. Three and five year changes in intraocular pressures after clear corneal phacoemulsification in open angle glaucoma patients, glaucoma suspects, and normal patients. J Glaucoma. 2006;15:494-8.

14. Mansberger SL, Gordon MO, Jampel $\mathrm{H}$, et al. Reduction in intraocular pressure after cataract extraction: the ocular hypertension treatment study. Ophthalmology. 2012;119:1826-31.

15. Zaarour K, Abdelmassih Y, Arej N, Cherfan G, Tomey KF, Khoueir Z. Outcomes of micropulse transscleral cyclophotocoagulation in uncontrolled glaucoma patients. J Glaucoma. 2019;28:270-275.

16. Preda MA, Karancsi OL, Munteanu M, Stanca HT. Clinical outcomes of micropulse transscleral cyclophotocoagulation in refractory glaucoma-18 months followup. Lasers Med Sci. 2020;35:1487-91.

17. Ching HY, Wong AC, Wong CC, Woo DC, Chan CW. Cystoid macular oedema and changes in retinal thickness after phacoemulsification with optical coherence tomography. Eye. 2006;20:297-303.

18. Lobo CL, Faria PM, Soares MA, Bernardes RC, Cunha-Vaz JG. Macular alterations after small-incision cataract surgery. J Cataract Refract Surg. 2004;30:752-60.

19. Williams AL, Moster MR, Rahmatnejad K, et al. Clinical efficacy and safety profile of micropulse transscleral cyclophotocoagulation in refractory glaucoma. J Glaucoma. 2018;27:445-9.
20. Perez Cl, Han Y, Rose-Nussbaumer J, Ou Y, Hsia YC. Neurotrophic keratitis after micropulse transscleral diode laser cyclophotocoagulation. Am J Ophthalmol Case Rep. 2019;15:100469.

\section{AUTHOR CONTRIBUTIONS}

$A D$ participated in the surgical interventions, data collection, statistical analysis and is the primary author. TS, LD, SG, AA participated in data collection. SG, IR, KSL participated in surgical interventions. AK participated in the statistical analysis. KSL is the principal investigator and corresponding author.

\section{FUNDING}

The Iridex Company provided the laser probes to St. Thomas Hospital, but they did not have any influence in conducting the study, data collection/analysis and paper preparation.

\section{COMPETING INTERESTS}

KSL has received research grants and lectures fees from Iridex Inc.

\section{ADDITIONAL INFORMATION}

Correspondence and requests for materials should be addressed to Kin Sheng Lim.

Reprints and permission information is available at http://www.nature.com/ reprints

Publisher's note Springer Nature remains neutral with regard to jurisdictional claims in published maps and institutional affiliations.

(i) Open Access This article is licensed under a Creative Commons Attribution 4.0 International License, which permits use, sharing, adaptation, distribution and reproduction in any medium or format, as long as you give appropriate credit to the original author(s) and the source, provide a link to the Creative Commons license, and indicate if changes were made. The images or other third party material in this article are included in the article's Creative Commons license, unless indicated otherwise in a credit line to the material. If material is not included in the article's Creative Commons license and your intended use is not permitted by statutory regulation or exceeds the permitted use, you will need to obtain permission directly from the copyright holder. To view a copy of this license, visit http://creativecommons. org/licenses/by/4.0/.

(c) The Author(s) 2021 